\title{
LEGAL TECH Y EL ESTADO PERUANO
}

\author{
Legal teCH AND the PERUVIAN State
}

Fernando Martín Robles Sotomayor* Universidad Alas Peruanas

\section{Resumen}

El Estado, dentro de una política de gobierno digital, viene implementando una serie de procedimientos administrativos por medios electrónicos, accesibles con el DNI electrónico, comenzando así un uso intenso de documentos electrónicos con firma digital. Esta transformación digital se conoce con el nombre de Legal Tech.

Dentro de esta nueva cultura digital, se requiere que el profesional del Derecho aprenda a utilizar las nuevas tecnologías para hacer más eficaz y eficiente su trabajo; por lo que el abogado del presente (y el del futuro) debe evolucionar a la velocidad que evolucionan las tecnologías de la información y la comunicación.

Palabras clave: Derecho público; informática; abogado; gobierno digital; tecnología legal.

\section{Abstract}

The State, within a Digital Government policy, has been implementing a series of administrative procedures by electronic means, accessible with the electronic ID, beginning in that way with an intense use of electronic documents with digital signature. This digital transformation is known as Legal Tech.

Within this new digital culture, the legal professional is required to learn to use new technologies to make his work more effective and efficient; Therefore, the lawyer of the present and even more of the future must evolve at the speed that information and communication technologies evolve.

Keywords: Public law; computer science; lawyer; digital government; Legal Tech.

* Doctor en Derecho por la Universidad Alas Peruanas. Profesor en la Academia de la Magistratura. Profesor e investigador en la Universidad Científica del Perú. 


\section{INTRODUCCIÓN}

El maestro mexicano Julio Téllez Valdez publicó, en 1987, la primera edición de su obra Derecho Informático, en la cual definía a la informática jurídica como «la técnica interdisciplinaria que tiene por objeto el estudio e investigación de los conocimientos de la informática general, aplicables a la recuperación de información jurídica, así como a la elaboración y aprovechamiento de los instrumentos de análisis y tratamiento de información jurídica necesarios para lograr dicha recuperación» (2004, p. 10). Posiblemente, en lo que pensaba era que un abogado fuese eficiente en el uso de un procesador de texto, como Word Star o Word Perfect (aún no existía Windows), y en él pudiese copiar y pegar información jurídica, resaltando sus textos con negrilla, subrayado o cursiva; pero difícilmente podría haber imaginado lo que era la transformación digital, hoy llamada Legal Tech.

Los abogados peruanos estamos ingresando a una etapa de cambio en nuestra forma de trabajo y de interactuar con las empresas, instituciones estatales, clientes y el propio Poder Judicial, que están dando paso a un uso intenso de las tecnologías digitales, por medio de las cuales toda nuestra labor profesional la podemos desarrollar desde nuestra oficina u hogar, con el sólo requerimiento de contar con un computador y acceso a internet, lo cual en el futuro incluso se podría concentrar en el celular o algún nuevo dispositivo electrónico.

\section{CAMBIO CULTURAL}

Cuando en la década de 1990 entramos a la quinta generación de la computación, con la difusión de las computadoras personales, se pensó que se reduciría el uso del papel; sin embargo, no fue así. Con la evolución y variedades de impresoras, que cada vez fueron adquiriendo mayor velocidad, el uso del papel aumentó significativamente, toda vez que continuamos viviendo en una cultura del papel a la que nos habíamos habituado a lo largo de siglos y de la cual no nos podíamos desprender tan fácilmente. Por ello el desarrollo de las computadoras fue acompañado de una mayor e impresionante producción de papel impreso, ya que todas nuestras relaciones personales y laborales siguieron funcionando en base a papeles.

La tecnología avanza y protege el ambiente; el Derecho y el hombre de leyes son lentos para adaptarse a los cambios, empero es lo que se viene con 
la cultura digital. Hace años vivimos en una Sociedad de la Información, caracterizada por el uso intenso de las nuevas tecnologías de la información y la comunicación (en adelante, TIC), pero lo que estuvimos haciendo es utilizar esas tecnologías adaptadas a la cultura del papel; hoy en día en nuestro país se está comenzando a vivir la transformación digital, conocida como Legal Tech en el ámbito del derecho, que implica un cambio cultural, en el cual dejaremos paulatinamente el uso del papel y lo reemplazaremos por los documentos electrónicos y otras herramientas tecnológicas que hacen innecesario el papel, reemplazándolo por el soporte digital, a ser utilizado para toda la documentación que comúnmente utilizamos los abogados en nuestras oficinas y distintas áreas de trabajo.

La relación entre el derecho y las TIC, es comúnmente conocida como Legal Tech. Según Carlos Caro, el desarrollo de la tecnología para el beneficio del Derecho no es tarea de abogados ni de asesores, es un trabajo de ingeniería que, mediante el uso del método experimental de ensayo-error, crea o descifra algoritmos y ecuaciones. Menciona, asimismo, que se trata de potenciar o transformar la actividad jurídica a través de la tecnología, en especial de los medios digitales, incluyendo, desde un software, hasta la inteligencia artificial, tanto para el ámbito público, como privado (Caro, 2019).

Paulatinamente, estamos reemplazando el documento en papel por el documento electrónico, la firma manuscrita por la firma digital, los voluminosos expedientes físicos con el expediente electrónico, los gigantescos y hacinados archivos de papel por los archivos digitales, todo ello es posible gracias a la aplicación del principio de equivalencia funcional, mediante el cual se cumple con el medio digital, con las mismas funciones que su equivalente en forma física, teniendo ambos en consecuencia, el mismo valor legal.

\section{LEGAL TECH EN EL ESTADO PERUANO}

La Organización de las Naciones Unidas (ONU. E-Goverment development) define al gobierno electrónico como «[1]a utilización de Internet y el World Wide Web para entregar información y servicios del gobierno a los ciudadanos». Podríamos decir, entonces, que el gobierno electrónico es el uso de las TIC en la administración pública para mejorar la información y los servicios ofrecidos a la ciudadanía, orientar la eficacia y eficiencia de su gestión e incrementar sustantivamente la transparencia del sector público 
y la participación ciudadana. La Oficina Nacional de Gobierno Electrónico e Informática (ONGEI) se encargó de conducir por más de 10 años las políticas públicas sobre Gobierno electrónico; el impulso tecnológico en nuestra sociedad ha dado lugar a nuevas expectativas y planteamientos ad portas de la transformación digital, lo que dio lugar a la creación de la Secretaría de Gobierno Digital en su reemplazo.

Si bien han existido una serie de obstáculos para el desarrollo del gobierno electrónico en nuestro país, como, por ejemplo, el insuficiente capital humano competente en el uso de las TIC, la falta de infraestructura tecnológica a nivel nacional y los recursos económicos, que no alcanzan para construir un sistema global de e-goverment, consideramos que el obstáculo principal ha sido el aspecto cultural, siendo el ámbito legal uno de los más incrédulos al ingreso de las tecnologías digitales, ya que como se pregunta Caro (2019): «iPodemos confiar en los algoritmos para sentenciar por ejemplo un caso de alimentos y patria potestad?, ¿puede un «juez» con inteligencia artificial decidir si el imputado es culpable o inocente con base en la big data y las pruebas del caso?, ¿podemos aceptar que el machine learning arribará a soluciones justas?».

A pesar de ello, en los últimos ańos, se ha dado un nuevo enfoque al desarrollo del gobierno digital, entendido como el uso estratégico de las tecnologías digitales y datos en la Administración Pública para la creación de valor público, en el que se priorizan actividades de gestión e implementación en materia de tecnologías digitales, identidad digital, servicios digitales, arquitectura digital, interoperabilidad, seguridad digital y datos, todo enfocado en el ciudadano, a fin de brindarle procesos, datos, contenidos y servicios digitales de valor. Con la aprobación de la «Ley de Gobierno Digital» ${ }^{1}$, se inicia en el sector público peruano una transformación digital, conocida en el ámbito del derecho como Legal Tech. Esto tiene una significativa influencia en el ambiente y la economía, menos papel, menos tala de árboles, sólo el Estado tiene un gasto anual aproximado de 400 millones de soles en papel, impresoras, repuestos y accesorios para su funcionamiento; por eso, para entender mejor lo expuesto, es necesario realizar una corta reseña a los avances en la implementación de las tecnologías de la información y la comunicación en la gobernanza digital peruana.

1 Aprobada por Decreto Legislativo N. ${ }^{\circ} 1412$ del 12 de setiembre de 2018. 


\subsection{Interoperabilidad}

Mediante el Decreto Legislativo N. ${ }^{\circ} 1246$ del 10 noviembre de 2016, se dan diversas normas sobre simplificación administrativa en el Estado peruano, pero todas ellas basadas en el concepto de interoperabilidad, mediante el cual las entidades públicas pueden compartir la información que poseen y de manera gratuita. Lo más interesante del caso es que dicha norma prohíbe que las entidades exijan a los ciudadanos la información que puedan obtener gracias a la interoperabilidad, cuyo avance es importante, puesto que al finalizar el año 2018, 296 entidades públicas se encuentran conectadas a la Plataforma de Interoperabilidad del Estado peruano (PIDE), con un valor significativo para los ciudadanos y abogados, que ven simplificada su intervención ante el Estado, al ya no tener que presentar abundante documentación en papel para el trámite o procedimiento administrativo que requieran, con un importante ahorro para el Estado estimado en 136 millones de soles durante el año 2018 (Secretaría de Gobierno Digital, 2019).

Por otro lado, para ayudar a la simplificación administrativa y los servicios online, el Banco de la Nación implementó pagalo.pe, servicio que le permite al ciudadano pagar en línea, con tarjeta de débito o de crédito, más de 150 tasas de procedimientos administrativos pertenecientes a diversas entidades del Estado peruano y que irán en aumento.

\subsection{Plataforma digital única gob.pe}

Mediante el Decreto Supremo N. ${ }^{\circ}$ 033-2018-PCM, del 23 de marzo de 2018, se crea la Plataforma Digital Única del Estado peruano, a través de la cual los ciudadanos pueden acceder a información y servicios del Estado de forma clara, basado en una experiencia sencilla, consistente e intuitiva, lo que constituye una importante evolución del Portal web de servicios al ciudadano y las empresas, y lo convierte en un efectivo medio de comunicación digital del ciudadano con el Estado peruano.

En dicha Plataforma, se pueden encontrar más de 49 mil trámites ante el Estado peruano, los cuales progresivamente se irán implementando online, priorizándolos en base a criterios de demanda, impacto en la vida del ciudadano, viabilidad y normatividad vigente, reuniendo en una única plataforma virtual los servicios públicos digitales, caracterizados por ser automáticos, no presenciales y utilizan intensamente las TIC para la pro- 
ducción y acceso a datos, servicios y contenidos de valor público para las personas en general. A estos trámites, los ciudadanos podrán acceder haciendo uso del Documento Nacional de Identidad electrónico (eDNI), cuya difusión comenzó a realizarse en el año 2013 y se estima que para el año 2021, 20 millones de peruanos cuenten con ese moderno documento de identidad, que lleva un chip incorporado en una tarjeta de policarbonato, que se asemeja a las tarjetas bancarias y que permite, además de identificar al ciudadano, realizar la firma digital y votar electrónicamente.

\subsection{Expediente y notificación electrónica en el Poder Judicial}

Esta es una de las principales áreas del desempeño laboral de los abogados, y por ello el Poder Judicial ha sido muy cuidadoso en implementarlo desde el año 2010, con la notificación electrónica se comunica las resoluciones judiciales, en forma rápida y segura, a través de un sistema de casillas electrónicas que el propio Poder Judicial confiere gratuitamente. Al principio, fue una práctica que trajo muchas dudas, toda vez que los abogados formados en una cultura del papel encontraban raro no recibir su cédula de notificación. Sin embargo, su uso se ha ido masificando desde el año 2015, en el que se volvió obligatorio en los procesos judiciales, aplicándose progresivamente en los distintos distritos judiciales.

Pero fue a fines del año 2017 cuando el Poder Judicial empezó con cambios más significativos, al iniciar el uso del Expediente Judicial Electrónico (EJE), diferente a la consulta online de las resoluciones judiciales que venía siendo usado desde ańos anteriores, y comenzar a utilizar integralmente las tecnologías digitales, lo que significa que se deje de usar el papel y la firma manuscrita, con importante ahorro de espacio, tiempo y dinero, permitiendo que el abogado ya no tenga que estar trasladándose a las sedes judiciales, sino que pueda revisar el expediente online en su totalidad, servicio accesible las 24 horas del día y los 365 días del año, además le brinda la posibilidad de remitir escritos en los procesos judiciales que interviene, utilizando para ello su firma digital y el eDNI.

\subsection{Sistema Peruano de Información Jurídica (SPIJ)}

Las normas legales en papel están pasando a la historia, la versión digital accesible en la web del diario El Peruano cada día es más utilizada por los 
abogados. No obstante, el SPIJ, administrado por el Ministerio de Justicia y Derechos Humanos, se constituye — sin lugar a dudas - en la mejor fuente de información legal del Perú, pudiendo descargarse desde la Ley N. ${ }^{\circ} 1$ hasta las normas legales de última publicación, pues dicha plataforma se actualiza cada 24 horas, con la ventaja de que los dispositivos legales están concordados y actualizados, además de tener la opción de descarga en archivos con extensión .docx. El SPIJ se volvió gratuito a fines del año 2016, convirtiéndose en una destacada herramienta de Legal Tech para el abogado peruano, que le permite ahorrar el uso de grandes cantidades de papel, para ello necesitaúnicamente ingresar al SPIJ libre desde el buscador de Google o cualquier otro buscador-.

\subsection{Política «cero papel»}

Los discursos políticos por varios ańos han utilizado la política «cero papel» como parte de su retórica, pero lo cierto es que esta medida se viene impulsando desde el año 2014. Sin embargo, es recién con la interoperabilidad del Estado peruano y los más recientes adelantos tecnológicos que se está haciendo una realidad. Ya comentamos el importante avance en el Poder Judicial con el EJE, no obstante ya algunas entidades públicas estaban usando el expediente electrónico desde mucho antes, entre otras,la Superintendencia de Mercado de Valores (SMV) y el Registro Nacional de Identificación y Estado Civil (Reniec), con tendencia a su masificación, pues gracias al Decreto Legislativo N. ${ }^{\circ} 1310$ del 29 de diciembre de 2016 se ha dispuesto que todas las entidades del Poder Ejecutivo deban contar con procedimientos administrativos validados e interconectar sus sistemas de trámite documentario, habiendo intervenido la Secretaría de Gobierno Digital, con el desarrollo del Modelo de Gestión Documental (MGD), el que constituye un cambio fundamental en la forma cómo se desarrollan los procedimientos en las entidades públicas y traerá consigo avance tecnológico, de la mano con la protección del ambiente y los consecuentes beneficios económicos.

\section{CONCLUSIONES}

El avance del Legal Tech está dando sus primeros frutos y tiene una perspectiva de rápida implementación en el Perú, por lo que el abogado debe evolucionar y adaptarse rápidamente a esa nueva realidad. 
La generación automática de documentos electrónicos con contenido legal, la atención a los clientes online, los trámites administrativos o judiciales en línea, son algunos ejemplos del Legal Tech, que viene de la mano con toda la transformación digital del Estado peruano y promueve el ingreso a una cultura digital en la que se minimiza el uso del papel, y, además, repercute positivamente en una sociedad peruana, que cada vez más se convierte en una sociedad de la información.

\section{BIBLIOGRAFÍA}

Caro, C. (2019). Compliance y Legal Tech: los límites de la tecnología en el ejercicio del derecho. Revista web semanaeconómica.com. Disponible en: https:// semanaeconomica.com/compliance-30/2019/08/17/compliance-y-legal-tech/

Poder Judicial (2019). Expediente judicial electrónico. Disponible en: http://eje. pe/wps/wcm/connect/EJE/s eje/as inicio/

RENIEC (2019). Características del DNI electrónico. Disponible en: https:// portales.reniec.gob.pe/web/dni/caracteristicas

Secretaría de Gobierno Digital de la PCM (2019). Secretaría de Gobierno DigitalInteroperabilidad. Disponible en: https://www.gobiernodigital.gob.pe/interoperabilidad/

Téllez, J. (2008). Derecho Informático. 4. a edición. México D.F.: Mc Graw-Hill/ Interamericana, Instituto de Investigaciones Jurídicas de la Universidad Nacional Autónoma de México. 